\title{
Kalkım-Gönen Havzasındaki Kömürlü Tortulların Paleoekolojik Özellikleri, Kuzeybatı Anadolu
}

Palaeoecological aspects of coaly sediments from the Kalkım-Gönen Basin, Northwest Anatolia

\section{Sariye Duygu ÜÇBAŞ DURAK ve Mehmet Serkan AKKIRAZ}

Dumlupınar Üniversitesi, Mühendislik Fakültesi, Jeoloji Mühendisliği Bölümü, Merkez 43100 Kütahya (e-posta:duygu.ucbas@dpu.edu.tr)

\section{ÖZ}

Bu çalışma, Geç Oligosen-Erken Miyosen yaşlı Kalkım-Gönen Havzasındaki linyit içerikli tortulların paleoekolojik özelliklerini açıklamaktadır. Bu amaca ulaşmak için, çalışmalar Ünsa ve Metehan olmak üzere iki farklı alanda gerçekleştirilmiştir. Özel bir işletme olan Ünsa madencilik tarafından yaklaşık 187 m uzunluğunda karotlu sondaj yapılmıştır. Karot boyunca volkaniklerle ardalanmalı linyitli ince kırıntılı tortullar egemendir. Metehan bölgesinde de ince kırıntılı tortullarla ardalanmalı linyit düzeyleri bulunmaktadır. İstif yer yer birincil ve ikincil jips oluşumları içermektedir. Bölgedeki tortullar yoğun kırıklı ve kıvrımlı yapıya sahip olup kıvrım eksenlerinin yönlemleri genellikle kuzeydoğu-güneybatı yönlüdür. Bölgedeki açık işletmeden yaklaşık $30 \mathrm{~m}$ kalınlığa ulaşan ölçülü kesit alınmıştır. Ünsa sondaj örneklerinde, konifer ormanı bitkilerinden Pinaceae ve Cupressaceae ve ırmak kenarı bitki örtüsü elemanı Alnus formu çok yüksek yüzdelerdedir. Karışık orman topluluğunun temel elemanları Engelhardia, Castanea-Castanopsis, Quercus spp., ve her dem yeşil Quercus olup daha düşük miktarlarda kaydedilmiştir. Sporlar, otsul ve bataklık bitkileri en düşük miktarlarla temsil edilirler. Polen konsantrasyonundaki değişime bağlı olarak 3 farklı yersel polen zonu (Ü/1-3) ayırt edilmiştir. Metahan sporomorf toplulukları genellikle konifer ormanı (ayrılmamış Pinaceae), karışık orman topluluğu (Engelhardia, her dem yeşil Quercus, Quercus spp., Fagus, Carpinus) ve 1rmak kenarı bitkilerinin (Alnus) elemanlarınca zengindir. Sporlar göreceli olarak daha düşük miktarlardadır. Bataklık ormanı ve otsullar ise en düşük yüzdeleri oluşturmaktadır. Sayım sonuçları 2 farklı yersel polen alt zonunun varlığını belirtmektedir (M/1-2). Ayırt edilen bu alt zonlar Ünsa sporormorf topluluklarındaki Ü-2 zonuna karşılık gelmektedir. Her iki alanda tanımlanan polen toplulukları çökelim süresince yoğun bir orman örtüsünün varlığını göstermektedir. Bu ormanın içerisinde karışık orman bitkileri (her dem yeşil Quercus, Quercus spp., Engelhardia, CastaneaCastanopsis) ve koniferler (ayrılmamış Pinaceae, Cupressaceae, Keteeleria, Cedrus, Cathaya, Picea) bulunmaktadır. Irmak kenarlarında en bol bulunan bitki Alnus'tur. Bu ortamda Ulmus, Zelkova, Carya, 
Pterocarya ve Liquidambar gibi bitkiler ise daha az miktarda bulunmaktadır. Sayısal iklim sonuçları ve polen toplulukları, her iki alandaki (Kalkım-Gönen Havzası) linyitli tortulların nemli, yağışlı ve sıcak koşullar altında çökeldiğini göstermektedir.

Anahtar Kelimeler: Kalkım-Gönen Havzası, Kuzeybatı Anadolu, Oligo-Miyosen, Palinoloji

\section{ABSTRACT}

This study explains the palaeoecological aspects of the lignite-bearing sediments from the Late OligoceneEarly Miocene Kalkım-Gönen Basin. Studies were carried out in two different areas, Ünsa and Metehan. A core drilling was performed by a private company, Ünsa mining, about $187 \mathrm{~m}$ long. Fine grained lignite bearing deposits alternated with volcanics are dominant along the core. In the Metahan area, lignites with clastic deposits alternation are available as well. Sequence includes primary and secondary gypsum formations in some places. Sediments in the region is densely faulted and folded and orientations of fold axis is mainly northeast-southwest directed. A section was measured from the open pit mine reaching to approximately $30 \mathrm{~m}$ thick coniferous plants undifferentiated Pinaceae and Cupressaceae, riparian plant Alnus are in high percentages in the samples from the Ünsa drilling. The main elements of the mixed mesophytic forest are Engelhardia, Castanea-Castanopsis, Quercus spp., and evergreen Quercus that were recorded in minor quantities. Spores, herbaceous and swamp plants are represented by lowest quantities. Three local pollen zones (Ü/1-3) may be distinguished according to changes on pollen concentration. Metehan sporomorph associations are rich with respect to elements of coniferous forest (undifferentiated Pinaceae), mixed mesophytic forest (Engelhardia, evergreen Quercus, Quercus spp., Fagus, Carpinus) and riparian plants (Alnus). Spores are relatively in low amounts. Swamp forest and herbs constitute the lowest percentages. Counting results indicate the existence of two different local pollen sub-zones (M/1-2) corresponding to $\ddot{U}-2$ zone of the Ünsa sporormorph associations. Pollen assemblages identified in both areas indicate the presence of a dense forest cover during the deposition. Within this forest, mixed forest plants (evergreen Quercus, Quercus spp., Engelhardia, Castanea-Castanopsis) and conifers (undifferentiated Pinaceae, Cupressaceae, Keteeleria, Cedrus, Cathaya, Picea). Alnus is the most abundant plant on the edges of the river. In this environment, plants such as Ulmus, Zelkova, Carya, Pterocarya and Liquidambar occur in lesser amounts. Quantitative palaeoclimate results and pollen assemblages in both areas (Kalkım-Gönen Basin) indicate that lignite-bearing sediments were deposited under humid, hot and rainy conditions.

Key words: Kalkım-Gönen Basin, Northwest Anatolia, Oligo-Miocene, Palynology 


\section{GíRİŞ}

Kuzeybatı Anadolu, özellikle Trakya Havzası içerdiği linyit rezervi açısından önemli bir potansiyele sahiptir. Yapılan çalışmalar, linyitli tortulların çökeliminin çoğunlukla Oligosen süresince gerçekleştiğini göstermektedir (Bat1, 1996; İslamoğlu vd. 2010; Akgün vd. 2013; Demirtaş vd. 2015; Bozcu vd. 2015). Ayrıca kömürlü Oligosen istifleri sadece Trakya Havzası ile sınırlı kalmayıp, Biga yarımadasının kuzeyine, hatta Gökçeada'ya kadar uzanmaktadır (Akgün vd. 2013) (Şekil 1). Biga yarımadasında ekonomik linyit oluşumları ise Miyosen yaşı Çan Havzasında gözlenmektedir (Şekil 1). İzotop ve palinolojik çalışmalar, havzanın Erken-Orta Miyosen süresince çökeldiğini belirtmektedir (Siyako vd. 1989; Ediger, 1990; Bozcu vd. 2015). Ediger (1990) Çan Havzası (İntepe, Etili, Çan, Çomaklı, Helvacı, Kazıklı ve Şaroluk kesitleri) ve Gönen çevresi (Tütüncü ve Küpçıtı kesitleri) linyitlerinin palinostratigrafik özelliklerini incelemiştir. Palinolojik topluluk genellikle Leiotriletes microadriennis, Baculatisporites primarius, Laevigatosporites haardti, Pityosporites sp., Inaperturopollenites dubius, I. hiatus, I. polyformosus ve I. emmaensis formlarından oluşmaktadır. Araştırıcı elde ettiği topluluğun, Benda (1971)'de belirtilen "Eskihisar sporomorf topluluğu" ile korele edilebileceğini belirtmektedir ve çökelimin 15-20 my (Erken-Orta Miyosen) süresince gerçekleştiğini belirtmektedir. Diğer yandan son zamanlarda yapılan palinolojik çalışmalar, Çan Havzasındaki palinolojik topluluğun genellikle konifer ormanı bitkileri
(Pinus haploxylon tip, ayrılmamış Pinaceae, Picea ve Cupressaceae), karışık orman topluluğu bitkileri (Castanea-Castanopsis, Cyrillaceae-Clethraceae, Engelhardia, Ouercus robur ve Oleaceae) yaygin olduğunu göstermektedir (Demirtaş vd. 2015; Bozcu vd. 2015). Ayrıca ırmak kenarı bitki örtüsünün temel elamanı Alnus olup çok yüksek yüzdelidir.

Kalkım-Gönen Havzası ise Çan Havzasının güneydoğusunda yer almaktadır (Şekil 1). Havzanın uzanımı, KD-GB olup linyitli tortullar en iyi Tütüncü, Küpçıktı, Sebepli, Mancılık, Danişment ve Bengiler köyleri arasındaki açık işletmelerde gözlenmektedir (Şekil 2). Havzada yapılan palinolojik çalışmaların sayısı azdır (Üçbaş Durak ve Akkiraz, 2016). Araştırıcılar, Danişment, Linfa ve Bengiler çevresindeki linyitli tortulların yaşının, $\operatorname{Ar}^{40} / \mathrm{Ar}^{39}$ verilerine göre Geç Oligosen-Erken Miyosen (ŞattiyenAkitaniyen) olduğunu belirtirler (Üçbaş Durak ve Akkiraz, 2016). Danişment ve Linfa tortullarının yaşı Geç Oligosen, Bengiler tortullarının ise Erken Miyosen'dir. Her üç kesitten elde edilen palinolojik bulgular baskin bitki örtüsünün konifer ormanı, her dem yeşil ve yaprak döken karışık orman topluluğu ve ırmak kenarı bitki topluluklarından oluştuğunu göstermektedir. $\mathrm{Bu}$ çalışmada Kalkım-Gönen Havzasında, polenlere dayalı paleoekolojik verileri arttırmak için, Ünsa ve Metehan kesitlerinden yeni örnekler derlenerek palinolojileri incelenmiştir. Ünsa ve Metehan işletmesinden bölümsel kesitler ölçülmüştür (Şekil 2). 


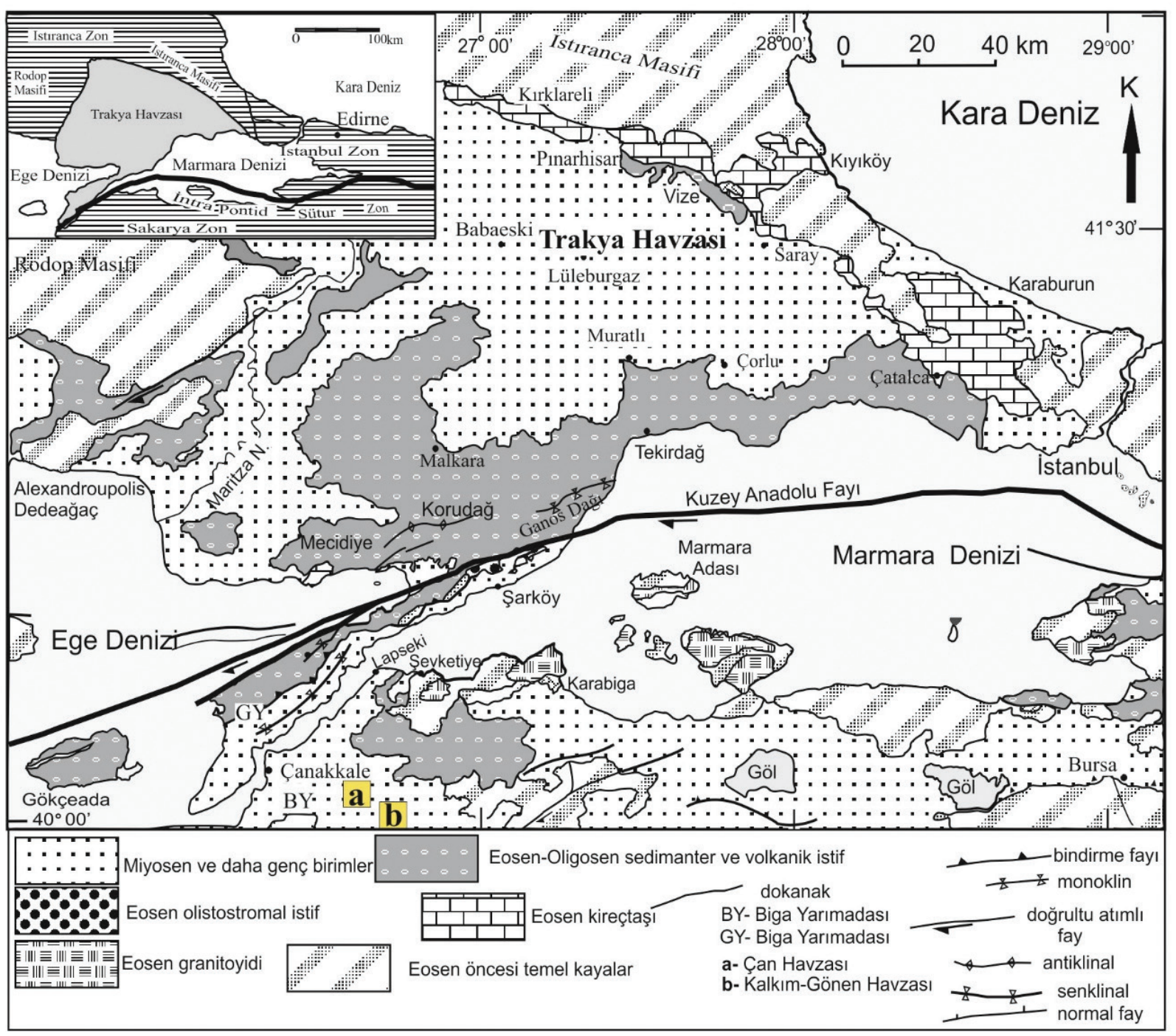

Şekil 1. Kuzeybatı Anadolu'nun (Trakya ve çevresi) jeolojik haritası. (a) Çan Havzası; (b) Kalkım-Gönen Havzası (Okay vd. 2010).

Figure 1. Geological map of northwest Anatolia (Thrace and surrounding). (a) Çan Basin; (b) Kalkım-Gönen Basin (from Okay et al. 2010).

\section{MATERYAL VE YÖNTEM}

\section{Materyal}

Bu çalışmada, Kalkım-Gönen havzasındaki Ünsa madencilik tarafindan açılmış sondaj karotu palinolojik açıdan örneklenmiştir. Toplam 52 örnek toplanmıştır (Şekil 3a). Bunların 34 tanesi sayım sonuçlarına uygun bulunmuştur (Şekil 6). Ayrıca Metehan yöresindeki bir açık işletmeden bölümsel bir kesit üzerinden toplam 26 örnek derlenmiş ancak 7 tanesi palinolojik açıdan değerlendirme için yeterli sporomorf içermektedir (Şekil 3b, 6b). 


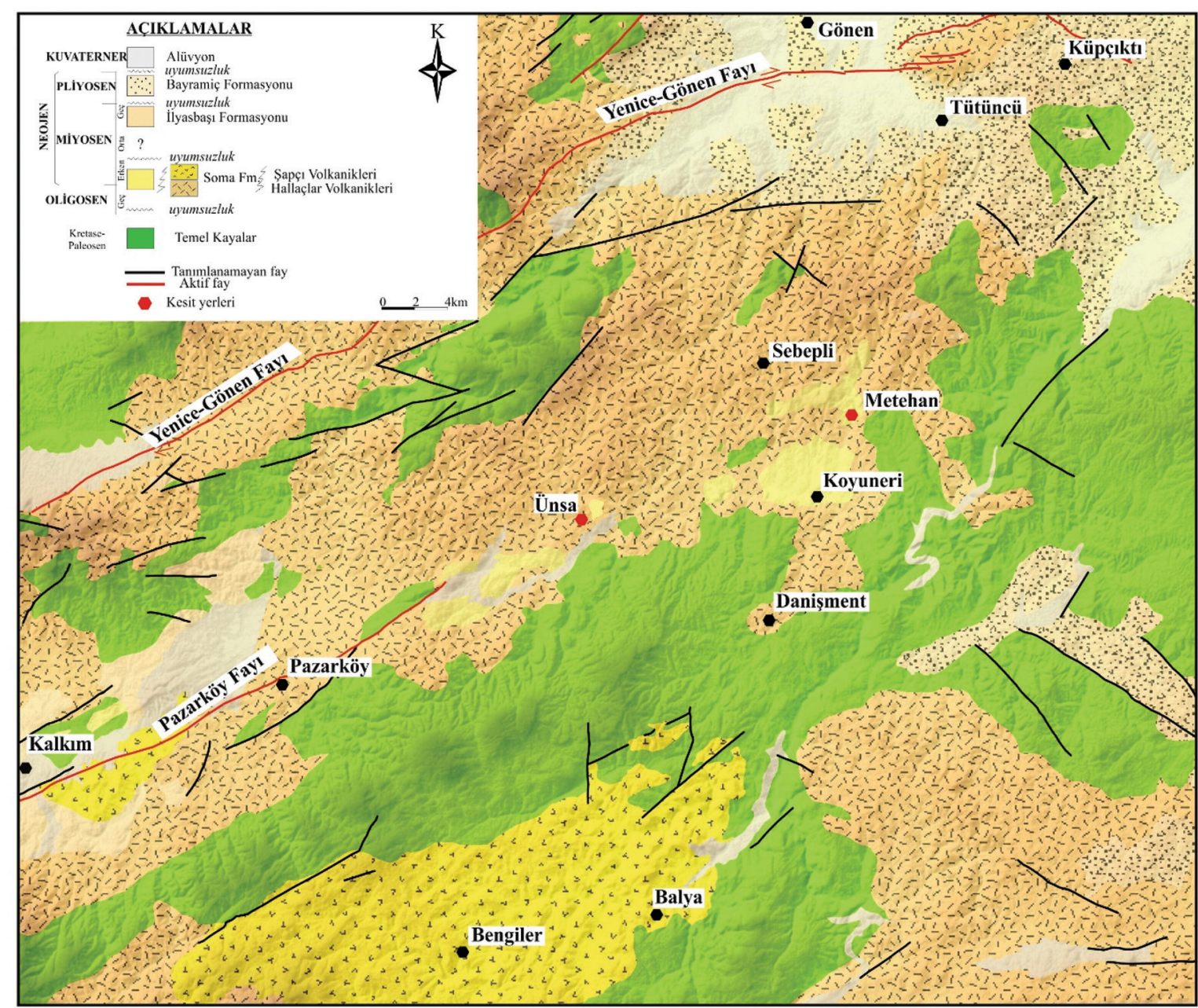

Şekil 2. Kalkım ve Gönen arasını gösteren jeolojik harita (Duru vd. 2007; Pehlivan vd. 2007; Akçay vd. 2008).

Figure 2. Geological map of the Kalkım and Gönen (Duru et al. 2007; Pehlivan et al. 2007; Akçay et al. 2008).

\section{Yöntem}

Araziden derlenen örnekler öğ̈̈ülmüş ve çeşitli kimyasal işlemlerden geçirilmiştir. Sırasıyla HCL (Hidroklorik asit (\% 32)), HF (Hidroflorik asit (\% 38-40)), Nitrik Asit (\% 65)+Potasyum klorat $\left(\mathrm{HNO}_{3}+\mathrm{KCLO}_{3}\right)$ uygulanmıştır. Son aşamada ise bazlardan $\mathrm{KOH}$ (Potasyum Hidroksit) kullanılmıştır. Dekantasyon sonucu örnekler, şişlere alınıp lamlar hazırlanmıştır. Genellikle her bir örnekten 2şer lam hazırlanarak incelenmiştir. Her bir örnek için en az 200 birey sayımı gerçekleştirilmiştir. Sayım sonuçları yüzdeye dönüştürülerek bir istatistik programı olan TILIA programında değerlendirilmiş ve polen yüzdelerindeki değişim ortaya konmuştur (Grimm, 1995). Sayısal iklim değerleri elde etmek için Coexistence Approach yöntemi kullanmıştır (Mosbrugger ve Ustecher, 1997). $\mathrm{Bu}$ çalışmada Çizelge 1'de belirtilen iklim değerleri hesaplanmıştır. Ayrıca elde edilen polenlerin botanik bağlılıkları ortaya çıkarıldıktan sonra, paleoekolojik gereksinimleri göz önünde bulundurularak gruplandırılmıştır (Şekil 8). 


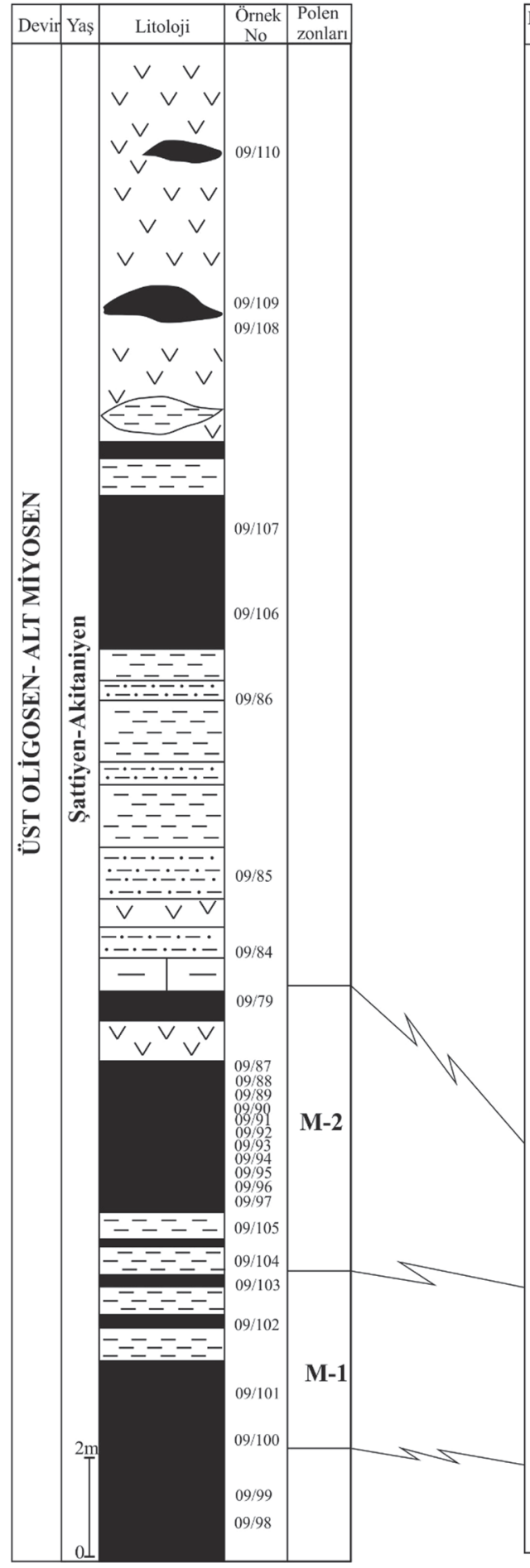

(b)

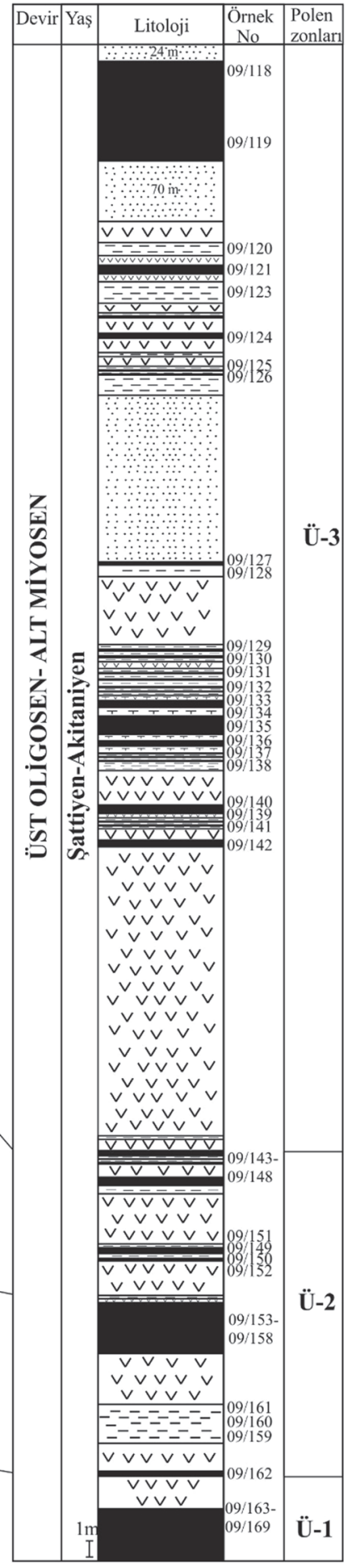

(a)

Şekil 3. Ünsa linyit işletmesine ait sondaj karotu (a); Metehan açık işletmesinden alınan bölümsel kesit (b). Figure 3. A borehole core from Ünsa coal pits (a); partial section from the Metehan open pit mine (b). 


\section{STRATÍGRAFİ}

Havzadaki, linyit içerikli tortulların temelini, Geç Paleozoyik-Erken Kretase yaşlı Sakarya zonu ve Geç Kretase yaşlı İzmir-Ankara zonu kayaları oluşturmaktadır (Duru vd. 2007; Pehlivan vd. 2007; Akçay vd. 2008). Bölgenin temel kayaları birbirleriyle tektonik ilişkili ve KD-GB uzanımlı ofiyolitik kayaçlar ve kireçtaşı bloklu filiş tipi kayalardan oluşan İzmir-Ankara ve genellikle amfibollü gnays, mermer, amfibolit, sillimanit gnays, biyotit gnays, granitik gnays, migmatit içeren Sakarya zonu kayalarından oluşmaktadır (Duru vd. 2007; Pehlivan vd. 2007; Akçay vd. 2008) (Şekil 1, 2).

Çizelge 1. İklimsel parametrelerin listesi ve kullanılan kisaltmalar

Table 1. A list of climate parameters and abbreviations.

Yıllık Ortalama Sicaklık $\left({ }^{\circ} \mathrm{C}\right)$ MAT

En Soğuk Ayın Ortalama Sıcaklığ $\left({ }^{0} \mathrm{C}\right) \mathrm{CMT}$

En Sicak Ayın Ortalama Sicaklığ $1\left({ }^{\circ} \mathrm{C}\right)$ WMT

Yıllık Yağış Miktarı (mm) MAP

En Nemli Ayın Yağış Miktarı (mm) HMP

En Kurak Ayın Yağı̧̧ Miktarı (mm) LMP

En Sıcak Ayın Yağış Miktarı (mm) WMP

Kömürlü Senozoyik istifi ise temel kayaları uyumsuz olarak üstlemektedir (Akgün vd. 1986; Siyako vd. 1989; Ediger, 1990; Ercan vd. 1990; Genç, 1998; İnci, 1998; Selim vd. 2006; Duru vd. 2007; Pehlivan vd. 2007; Akçay vd. 2008) (Şekil 1.3). Çalışma alanındaki Senozoyik yaşlı istif sırasıyla; Geç Oligosen-Erken Miyosen yaşlı yer yer altere andezit, bazaltik-andezitik lav ve piroklastiklerden oluşan Hallaçlar volkanikleri, Geç Oligosen - Erken Miyosen (ŞattiyenAkitaniyen) yaşlı linyit içerikli Soma Formasyonu,
Erken Miyosen yaşlı altta ignimbiritik asidik tüf, üst kesimlerinde asidik lavlar ve piroklastiklerden oluşan Şapçı volkanikleri, Geç Miyosen yaşlı İlyasbaşı Formasyonu ve Pliyosen yaşlı kırmızıkahverengi çakıltaşı, kumtaşı ve çamurtaşı içeren, alüvyon yelpazesi, örgülü ve menderesli akarsu çökellerinden oluşan Bayramiç Formasyonu'dur (Duru vd. 2007; Pehlivan vd. 2007; Akçay vd. 2008) (Şekil. 2). Kuvaterner yaşlı alüvyon tüm birimleri uyumsuz olarak örtmektedir.

\section{Soma Formasyonu}

Çalışmanın konusunu oluşturan Soma Formasyonu ilk kez Nebert (1978) tarafindan Manisa-Soma ve çevresindeki linyit içerikli tortullar için tanımlanmış ve adlandırılmıştır. Soma ve çevresinde yüzlek veren formasyon alttan üste doğru sırasıyla çakı1ltaşı, kumtaşı, çamurtaşı, alt linyit damarı, bol yaprak fosilli marn, silttaş1, gastropod ve bivalvialı kireçtaşı ve üst linyit damarından oluşmaktadır (Nebert, 1978; İnci, 1984, 1998; 2002; Akgün vd. 1986; Gemici vd. 1991; Akgün vd. 2007). Son zamanlarda yapılan çalışmalar Soma Formasyonunun Erken Miyosen'de oluştuğu belirtilmektedir (Kaya vd. 2007; Ersoy vd., 2014). Bu çalışmada da incelenen kömürlü istif aynı formasyon içinde ele alınmıştır (Duru vd. 2007; Pehlivan vd. 2007; Akçay vd. 2008) (Şekil 2).

\section{Ünsa Sondajı (Koord: 46732/18318)}

Ünsa kesitindeki istif volkaniklerle ardalanmalı ince kırıntılı tortullardan oluşmaktadır. Ocakta birbirinden farklı seviye ve kalınlıkta linyit damarları gözlenmektedir (Şekil 3). Açık işletmede linyitli birimler ile ince kırıntılı tortullar ardalanmalı olup, yer yer düşeye yakın tabaka konumlarına sahiptir(Şekil4). Ünsa alanında, Ünsa madencilik tarafından karotlu sondaj yapılmış 
olup kalınlığı 187 m'dir (Şekil 3a). Karotun üst bölümlerinde, linyit içerikli sarımsı renklerde kumtaşı baskın bir çökelim söz konusudur. Daha derinlere doğru tüfler baskın hale gelmektedir. Ayrıca farklı seviye ve kalınlıklarda kırıklı, belirgin katmanlı linyit damarları gözlenmektedir. Derinlerde sondajın üst bölümünde baskın olan kumtaşları yok olmaktadır ve egemen grimsi renklerdeki kiltaşları bulunmaktadır.

\section{Metehan Kesiti (Koord: 57732/22444)}

İstif yoğun bir şekilde deformasyona uğramıştır. $\mathrm{Bu}$ deformasyonların izleri olarak katmanlar bol çatlaklı ve yer yer kıvrımlıdır. Kıvrım eksenleri KD-GB yönlemine sahip olup genellikle dalımsızdır (Şekil 5a) Açık işletmeden elde edilen bölümsel kesitte (yaklaşık 30 m) birbirinden farklı seviyelerde kömür oluşumları gözlenmektedir. Altta yaklaşık $4 \mathrm{~m}$ kalınlığında bol gastropod fosilli linyit damarı bulunmaktadır (Şekil 3b). Üzerine ise $3 \mathrm{~m}$ kalınlığında kiltaşı linyit ardalanması gelmektedir. Üstte ise tekrar $3 \mathrm{~m}$ kalınlığında linyit gözlenmektedir. Yaklaşık $9 \mathrm{~m}$ kalınlığa ulaşan volkanik katkılı, kırıklı çatlaklı, çamurtaşı, kiltaşı marn ardalanması alttaki linyiti üstlemektedir. Üste doğru kiltaşı ara düzeyli, turba oluşumları mevcuttur (Şekil 3b). Arazi gözlemleri turbaların yoğun kükürt, birincil ve ikincil jips oluşumları içerdiğini göstermektedir. En üstte ise volkanokırıntılı tortullar ortalama $8 \mathrm{~m}$ kalınlığında olup merceksel linyit seviyeleri gözlenmektedir (Şekil 3 b ve $5 b)$. Bu kömür mercekleri de bol kükürt ve jips oluşumları içermektedir.

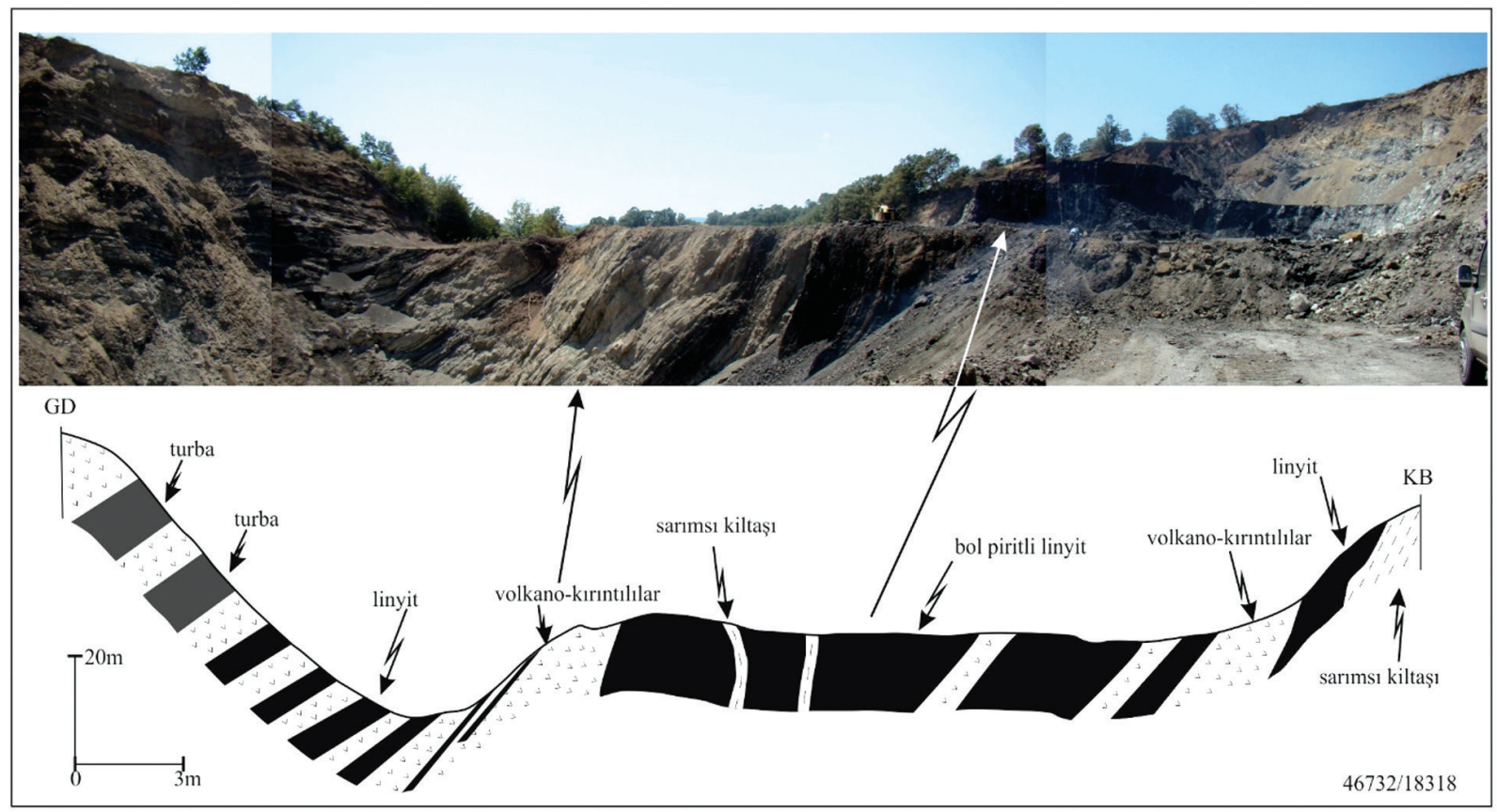

Şekil 4. Ünsa linyit işletmelerindeki deformasyona uğramış kömürler.

Figure 4. Coals deformed in the Ünsa lignite pits. 


\section{PALINOLOJI}

\section{Ünsa Sporomorf Toplulukları}

İncelenen örneklerde çeşitlilik fazla ancak bunlara ait yüzdeleri oldukça düşüktür. Polenler sporlara oranla daha yüksek yüzde ve çeşitliliğe sahiptir (Şekil 6a). Toplam 20 aile ve 35 cins tanımlanmıştır. Ünsa palinoflorasını oluşturan bitkiler içerisinde, tüm kesit boyunca, konifer ormanı bitkilerinden ayrılmamış Pinaceae ve Cupressaceae, karışık orman topluluğu içerisinde Quercus spp. ve ırmak kenarı bitki örtüsü içinde de Alnus formları baskındır. Sporlardan Schizaceae, Monoleiotriletes sp., Intrapunctisporis sp., Pteridaceae, Lycopodium, Sphagnaceae, Reticulatisporites sp., Extrapunctatisporis sp. ve Selaginella sp. çok düşük oranlarda (\%03) gözlenmektedir. Irmak kenarı bitkisi Alnus
09/145 numaralı örnekte en yüksek seviyeye ulaşmaktadır ( $\sim \% 80)$ (Şekil $6 \mathrm{a})$. Bu ortamdaki diğer bitkiler olan Ulmus, Zelkova, Pterocarya, Carya, Liquidambar ve Platanus/Salix düşük yüzdeli olup \%0-3,7 arasında değişmektedir. Karışık orman topluluğu içinde, her dem yeşil Quercus ve Quercus spp., formlarının yüzdesi \%0-14 arasındadır. Bu ortamın diğer formları olan Fagaceae, Fagus, Carpinus, Oleaceae, Betula, Corylus, Ilex, Acer, Juglandaceae, Celtis, Craigia ve Cycas miktarları \%0-2.4 ile temsil edilmektedir. Sucul bitkilerden Sparganiaceae \%0-1.9, otsul bitkilerden Poaceae, Compositae, Chenopodiaceae ve Ephedra çok düşük orandadır (\%0-1.6). Polen yüzdelerindeki değişim gözönünde bulundurulduğunda, birbirinden farklı 3 yersel polen zonu ayırtlanabilmiştir (Şekil 6a).

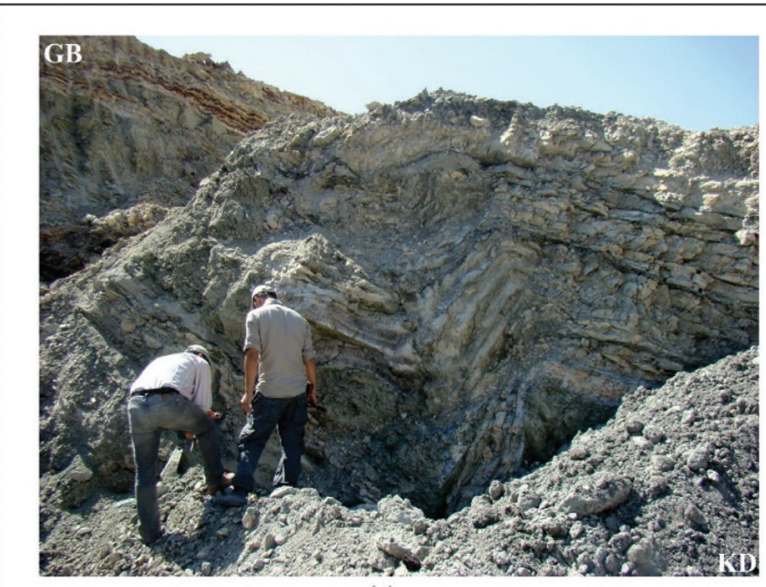

(a)

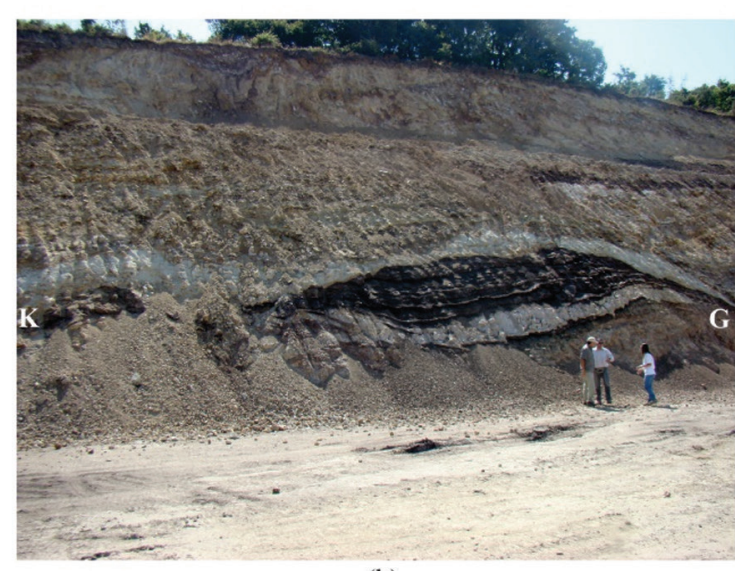

(b)

Şekil 5. Metehan linyit işletmelerindeki kiltaşlarındaki kıvrımlı yapı (a); istifin üst bölümlerindeki linyit merceği (b).

Figure 5. Folding of claystones in the Metehan lignite pits (a); lignite lense at the upper side of the sequence. 


\section{Ü-1 yersel polen zonu (örnek numaraları 09/163-169)}

Bu zonda 1rmak kenarı bitkisi Alnus (\%3.3-66.6) ve konifer ormanı bitkilerinden Cupressaceae (ortalama \%20) baskınlığı ile ayırt edilmektedir. Ayrıca yüksek bollukta konifer ormanı bitkilerinden ayırtlanmamış Pinaceae (ortalama \%6) tüm örneklerde gözlenmektedir. Karışık orman topluluğunun temel bitkileri Engelhardia (\%2.5), Castanea-Castanopsis (0-\%5.1), her dem yeşil Quercus (\%1-4.8) ve Quercus spp., (\%310.8)'dir.

\section{Ü-2 yersel polen zonu (örnek numaraları 09/144-162)}

$\mathrm{Bu}$ zonda Alnus çok yüksek bolluklarda kaydedilmiştir (\%28- 76,3). Koniferlerden ayrılmamış Pinaceae yüksek oranlarda bulunmaktadır ve 09/158 numaralı örnekte $\% 38$ bolluk oranına ulaşmaktadır (Şekil 6a). Bu zonda, çok düşük miktarlarda Cathaya, Cedrus, Picea, Pinus haploxylon tip, Pinus diploxylon tip koniferleri ortaya çıkmaktadır. Ayrıca CyillaceaeClethraceae, yaprak döken Quercus, Fagus, Carpinus, Oleaceae, Betula, Acer, Pterocarya, Myrica ve Ephedra formları da bu zonda ortaya çıkmaktadır. Cupressaceae miktarı Ü-1 zonuna göre daha düşük oranlardadır (ortalama \%3). Karışık orman topluluğu başlıca her dem yeşil Quercus ve Quercus spp., formlarının varlığ ile karakterize edilmektedir. $\mathrm{Bu}$ zonda, CastaneaCastanopsis tip 09/157-161 numaral1 örneklerde ortalama \%4.7 oranında bulunmaktadır. $\mathrm{Bu}$ oran zonun üst bölümlerine doğru azalmaktadır. Ayrica 09/157 numaralı örnekte her dem yeşil Quercus \%14.8 ve Quercus spp., ise \%11.2 bolluk oranlarına ulaşmaktadır (Şekil 6a).

\section{Ü-3 yersel polen zonu (örnek numaraları 09/119-143)}

$\mathrm{Bu}$ zon, ayrılmamış Pinaceae, Cupressaceae ve Alnus formlarının yüksek oranları ile ayrilırlar (Şekil 6a). Özellikle ayrılmamış Pinaceae (ortalama \%10) ve Cupressaceae (ortalama \%9) formlarının miktarları bu zonda artmaktadır. Karışık orman topluluğunun elemanları olan Engelhardia, Castanea-Castanopsis, her dem yeşil Quercus ve Quercus spp., ile sporlardan Polypodiaceae/Thelipteridaceae formları diğer zonlardaki gibi benzer oranlarda kaydedilmiştir. Sporlardan Osmunda 09/135 numaralı örnekte en yüksek değerine ulaşmaktadır (\% 9.8) (Şekil 6a).

\section{Metehan Sporomorf Toplulukları}

Burada kaydedilen formların çeşitliliği Ünsa kesitinden elde edilenlere göre daha düşüktür (Şekil 6b). Toplam 12 aile ve 20 cins tanımlanmıştır. Topluluklarda polenler sporlara oranla daha fazladır. Polenler genellikle, konifer ormanı, her dem yeşil ve yaprak döken karışık orman topluluğu ve ırmak kenarı bitki örtüsünün elemanları bakımından zengindir (Şekil 6b). Bataklık orman bitkileri ve otsullar daha düşük miktarlardadır. Sporlar, Polypodiaceae/Thelipteridaceae (ortalama $\% 1.5$ ) ve Pteridaceae (\%1'den az) formlarının düşük miktarları ile karakterize edilmektedir. Topluluklarda, conifer ormanı bitkilerinden ayrılmamış Pinaceae (ortalama \%15), her dem yeşil ve yaprak döken karışık orman topluluğu bitkileri, her dem yeşil Quercus (ortalama \%5), Quercus spp., (ortalama (\%6.8) ve Carpinus (ortalama \%2), 1rmak kenarı bitki örtüsü ise Alnus (ortalama \%16.4) formları yüksek oranlarda bulunmaktadır. Polen yüzde değişimlerine göre 2 farklı polen zonu ayırtlanabilir. Tanımlanan bu zonlar Ünsa topluluklarında belirtilen Ü-2 zonuna 
karşılık gelmektedir. Bu yüzden tanımlananlar alt zon olarak belirtilmektedir.

\section{M-1 yersel polen alt zonu (örnek numaraları 09/100,102,103)}

Bu zon, her dem yeşil Quercus (09/102 numaralı örnekte \%20.8'e ulaşan bolluk), Quercus spp., (09/102 numaralı örnekte \%18'e ulaşan bolluk) ve Alnus (09/103 numaralı örnekte \%31.2'e ulaşan bolluk) formlarının yüksek miktarları ile ayrilır. Ayrica burada, Castanea-Castanopsis 09/100 numaralı örnekte \%14.8 bolluk oranına ulaşmaktadır(Şekil6b).Engelhardia,Cupressaceae ve Carpinus formları hemen hemen her örnekte düşük miktarlarda kaydedilmiştir. Tanımlanan M-1 zonu, Ünsa sporomorf topluluklarında ayırt edilen Ü-2 zonu ile korele edilebilir. Her iki zonda da Cupressaceae miktarları düşüktür. Castanea-Castanopsis Ü-2 zonundaki 09/157161 numaralı örneklerde yüksek oranlardadır. Formun 09/100 numaralı örnekteki artış1, Ü-2 zonundaki örneklerden bir tanesine karşılık geldiği söylenebilir (olasılıkla 09/158 numaralı örnek). Benzer şekilde her dem yeşil Quercus ve Quercus spp., nin 09/102 numaralı örnekteki artışları, Ü-2 zonundaki 09/157 numaralı örnekteki artışları ile benzerlik sunmaktadır (Şekil 6b).

\section{M-2 yersel polen alt zonu (örnek numaraları 09/104, 105,87,79)}

$\mathrm{Bu}$ zon, ayrılmamış Pinaceae (09/87 numaralı örnekte \% 31.2 ye ulaşan bolluk), Quercus spp., (09/105 numaralı örnekte \% 19.8'e ulaşan bolluk) formlarının yüksek miktarları ile ayırt edilir (Şekil 6b). Ayrıca bu zonda düşük miktarlarda Polypodiaceae/Thelipteridaceae, Cupressaceae, Engelhardia, Castanea-Castanopsis ve Carpinus bitkilerini de içermektedir. M-1 zonunda bol miktarda gözlenen Alnus formu bu zonda düşük yüzdelerde (ortalama \%8) kaydedilmiştir. Tanımlanan bu zon olasilıkla Ü-2 zonunun daha üst bölümlerine karş1l1k gelebilir. Ünsa topluluklarının Ü-2 zonu boyunca ve Metehan topluluklarında Cupressaceae formlarının az oranda bulunması bu sonucu doğurmaktadir. Ü-1 ve Ü-3 zonlarında Cupressaceae yüzdesi çok fazladır. Ayrıca Quercus spp., formunun Ü-2 zonundaki 09/147 numaralı örnekte göreceli olarak yüksek (\%8'e ulaşan bolluk) değerlerde kaydedilmiştir.

\section{PALEOVEJETASYON}

\section{Ünsa sondajı}

Sporomof bulguları çökelim süresince çevre yükseltilerde bitki örtüsü hakkında bilgi sağlamaktadır. Her üç zonda (Ü-1,2,3) yüksek yüzdeli, ayrılmamış Pinaceae (çam), Cupressaceae (servigiller), Quercus spp., (meşe) ve Alnus (kızılağaç) bitkileri gözlenmektedir. Bu bitkiler çevredeki yükseltilerde yoğun bir orman örtüsünü belirtmektedir. $\mathrm{Bu}$ orman koniferler ve 1 rmak kenarında yaşayan bitkilerce zengindir. Konifer ormanı bitkileri içinde Cedrus (sedir) ve Picea (ladin) bitkilerinin çok düşük miktarda (\%1'den az) bulunması dağların çok yüksek olmadığı anlamına gelmektedir. Özellikle Ü-1 zonunda bu formlar kaydedilmemiştir (Şekil 6a). Her dem yeşil ve yaprak döken karışık orman topluluğu bitkileri ise bu konifer ormanı içerisinde daha düşük miktarlarda bulunmaktadır. Bataklık orman bitkileri, sucul bitkiler ve otsullar ise çok düşük miktarlardadır. Sporlar ise bu orman içindeki daha alttaki gölgelik alanlardaki bitki örtüsünü oluşturmaktadır. Karışık orman topluluğu genellikle Quercus spp. her dem yeşil Quercus, Castanea-Castanopsis (kestane) ve Engelhardia (ceviz) gibi düşük orandaki bitkilerden oluşmaktadır. Irmak kenarı bitki örtüsü egemen 
olarak Alnus bitkisinin baskınlığ ile karakterize edilir. $\mathrm{Bu}$ ortamda daha düşük miktarlarda, Ulmus, Zelkova (karaağaç), Pterocarya, Carya (cevizgiller) ve Liquidambar (sığla) bitkileri bulunmaktadır. Bataklıkta çok düşük oranlarda, Nyssa (sakız ağac1), Myrica (mersin), Magnolia (manolya) ve Taxodiaceae (selvigiller) bitkilerini içermektedir.

\section{Metehan kesiti}

Ünsa sondajındaki tanımlanan baskın formlar burada da tanımlanmaktadır(Şekil6b). Topluluklar, konifer, 1rmak kenarı ve her dem yeşil ve yaprak döken karışık orman toplulukları bakımından zengindir. Ünsa'dan farklı olarak, karışık orman topluluğunu oluşturan bitkilerin miktarları biraz daha fazladır. Bataklık ortam bitkileri ve otsullar çok düşük yüzdelidir. Sporların çeşitliliği ve yüzdeleri düşüktür. Konifer ormanı baskın olarak ayrılmamış Pinaceae'den oluşmaktadır ve M-1 alt zonunda yüzdeleri az M-2 alt zonunda ise artmaktadır. Karışık orman topluluğu bitkileri egemen olarak her dem yeşil Quercus ve Quercus spp., bitkilerinden oluşmaktadır. Alnus baskın 1rmak kenarı bitki örtüsü söz konusudur. M-1 alt zonundaki miktarı, M-2 alt zonuna göre daha fazladır. Topluluklarda ayırt edilen M-1 ve M-2 yersel polen alt zonları, Ünsa'da tanımlanan Ü-2 zonuna karşı1lık gelmektedir (Şekil 6b). Bunun sebebi, Ü-2 zonu ve M-1 ve M-2 alt zonlarında Cupressaceae bitkisinin çok düşük yüzdeli oluşuyla açıklanabilir.

\section{PALEOÍKLIMM}

\section{Ünsa Sondajı}

Toplanan örneklerin 15 tanesi sayısal iklim sonuçlarınauygunbulunmuştur(Şekil 7a). Çökelim süresince, y1llık ortalama sıcaklık değerleri (MAT) 17-21.1 ${ }^{\circ} \mathrm{C}$, kış sıcaklı̆̆ 1 (CMT) $6.2-15.6^{\circ} \mathrm{C}$, yaz
Sıcaklığı (WMT) 26.5-28.1 ${ }^{\circ} \mathrm{C}$, y1llık yağış miktarı (MAP) 897-1322 mm, en nemli ayın yağış miktarı (HMP) 150-200 mm, en kurak ayın yağış miktarı (LMP) 17-32 mm ve sıcak ayın yağış miktarı (WMP) 84-213 mm arasında değişmektedir (Şekil 7a). Ancak istif boyunca ortalama iklim değerleri alttan üste doğru salınım göstermektedir. Ayrıca her üç zon boyunca sıcaklık belirten mezotermik bitkilerin baskınlığı ve düşük orandaki megamezotermik ve her dem yeşil Quercus bitkilerinin varlığı iklimin sıcak olduğunu göstermektedir (Şekil 8a). İstif boyunca soğuk iklim koşullarını yansitan Cedrus gibi mikrotermik ve Poaceae, Chenopodiaceae, Asteraceae ve Ephedra gibi otsul bitkilerin düşük oranda olması bu sonucu desteklemektedir. Ayrıca tüm örneklerde Alnus ırmak kenarı bitkisinin yüksek yüzdeli olması çökelim süresince 1lıman iklim ve yağışın fazla olduğunu belirtmektedir (Şekil 6a). Sayısal iklim sonuçları da bunu desteklemektedir. Alnus Ü-1 zonu boyunca yüksek yüzdelidir. Ancak zonun üst bölümlerindeki 09/162 numaralı örneğe doğru aniden \% 6 oranına düşmektedir (Şekil 6a). Bu düşüş, ortalama iklim eğrilerinde sola sapmayla belirmektedir. MAT, CMT, WMT'nin ortalama sıcaklık değerleri 09/162 numaralı örneğe doğru azalmaktadır. Ayrıca HMP ve WMP'nın ortalama yağış değerleri de benzer şekilde düşüş göstermektedir. Ü-2 zonu boyunca Alnus çok yüksek yüzdelere ulaşmaktadır. İklim değerleri de Ü-1 zonunun alt bölümlerindeki değerlere ulaşmaktadır. Ü-3 zonunda göreceli olarak yüksek yüzdeli mikrotermik elementler ve otsulların düşük orandaki varlıkları yüksek topoğrafyadaki daha serin iklim koşullarını belirtmektedir (Şekil 8a). Ancak havza kenarındaki turba bataklıklarında, Alnus, Cupressaceae, Taxodiaceaee, Nyssa ve Myrica gibi mega-mezotermik ve mezotermik bitkilerin varlığı sıcak koşulların hüküm sürdüğünü göstermektedir. 


\section{Metehan Kesiti}

Sayımı yapılan örneklerin 5 tanesi sayısal iklim değerleri elde etmek için uygun bulunmuştur (Şekil 7b). Elde edilen değerler, Ünsa sondajından elde edilen sonuçlarla karşılaştırabilecek niteliktedir. Ancak değerler daha geniş aralıklar sunmaktadir. Sirasiyla, MAT=13.8-21.1, CMT= 5.6-15.6 ${ }^{\circ} \mathrm{C}, \mathrm{WMT}=20.6-28.1{ }^{\circ} \mathrm{C}, \mathrm{MAP}=740-$ $1322 \mathrm{~mm}, \mathrm{HMP}=150-303 \mathrm{~mm}, \mathrm{LMP}=5-43 \mathrm{~mm}$ ve $\mathrm{WMP}=79-214 \mathrm{~mm}$ sayısal değerleri elde edilmiştir (Şekil 7b). Ayrıca tanımlanan M-1 ve M-2 alt zonları (Ü-2 zonu) arasında belirgin bir değişim gözlenmemektedir (Şekil 7b). Ancak M-1 alt zonunda daha yüksek yüzdeli mezotermik elementler bulunmaktadır (Şekil 8b). Bu, Alnus, her dem yeşil Quercus ve Taxodiaceae formlarının artışı ile ilgilidir ve çökelim süresince yoğun yağış olduğu anlamına gelmektedir. İstif boyunca mega- mezotermik Engelhardia, Castanea-Castanopsis, Cyrillaceae-Clethraceae ve Myrica bitkilerinin varlığı da iklimin sıcak olduğunu belirtmektedir. M-2 alt zonunda Alnus ve Taxodiaceae ve Pterocarya bitkileri azalmaktadır. Ancak, bataklık ortamı bitkilerinden Platanus/Salix ve Myrica artmaktadır. Bu da M-1 ve M-2 altzonları arasında yağış miktarında belirgin bir değişimin olmadığını göstermektedir. Bozukov vd. (2008) Bulgaristan'daki linyit içerikli tortullarda yapmış olduklarıçalışmada GeçOligosen süresinceiklimde bir 1sınma ve Oligosen-Miyosen geçişinde ise bir soğumadan bahsetmektedir. Diğer yandan, Akgün vd. (2007) Geç Oligosen'den Erken Miyosen'e geçişte sıcaklık artışını vurgulamaktadırlar. Her iki kesitten elde edilen sıcaklıklar tortulaşmanın sıcak ve yağışı koşullarda gerçekleştiğini göstermektedir (Şekil 7b).
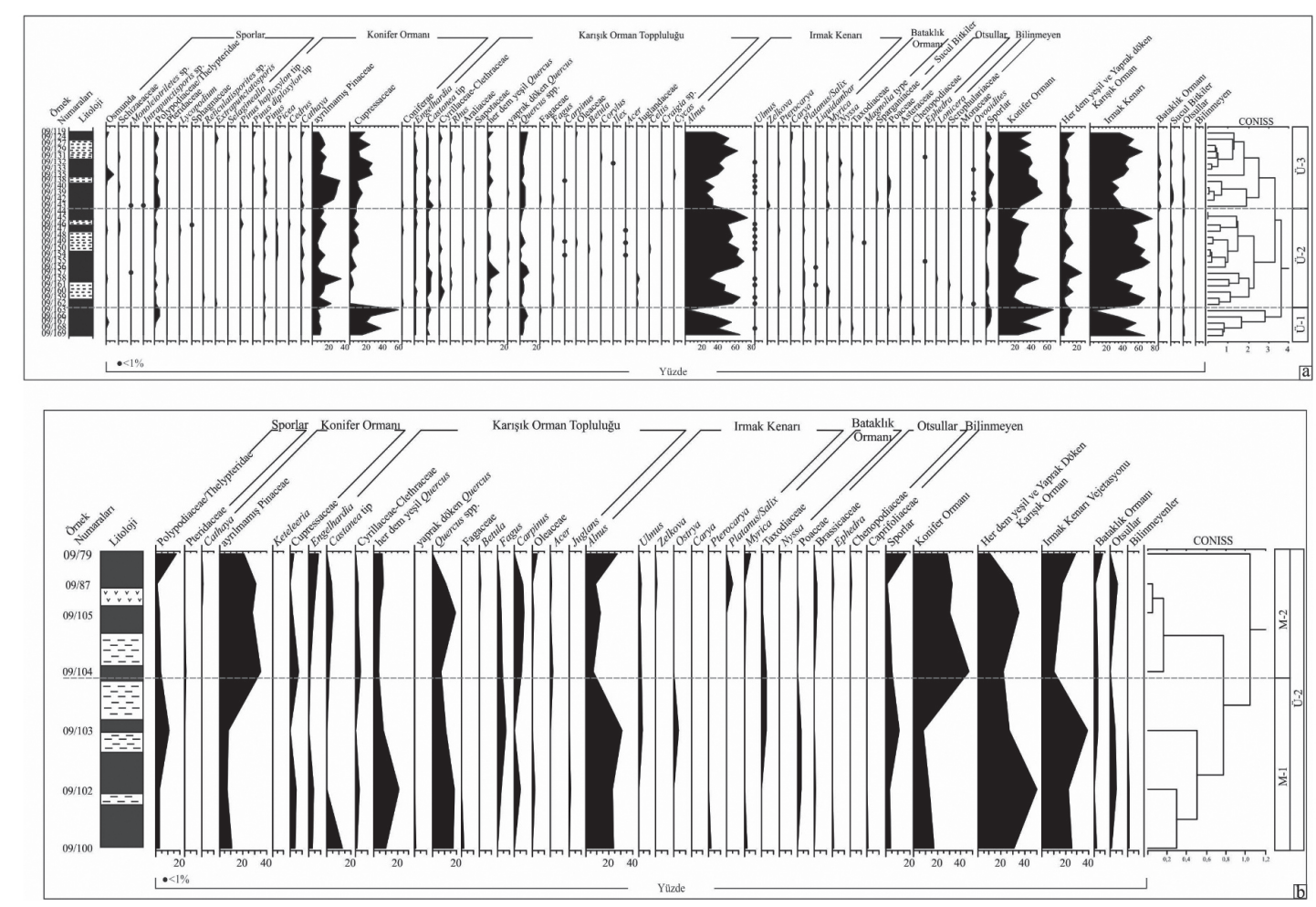

Şekil 6. Her bir örneğin yüzdelerini gösteren polen diyagramları. (a) Ünsa; (b) Metehan.

Figure 6. Pollen diagrams indicating the percentages of each samples. (a) Ünsa; (b) Metehan. 

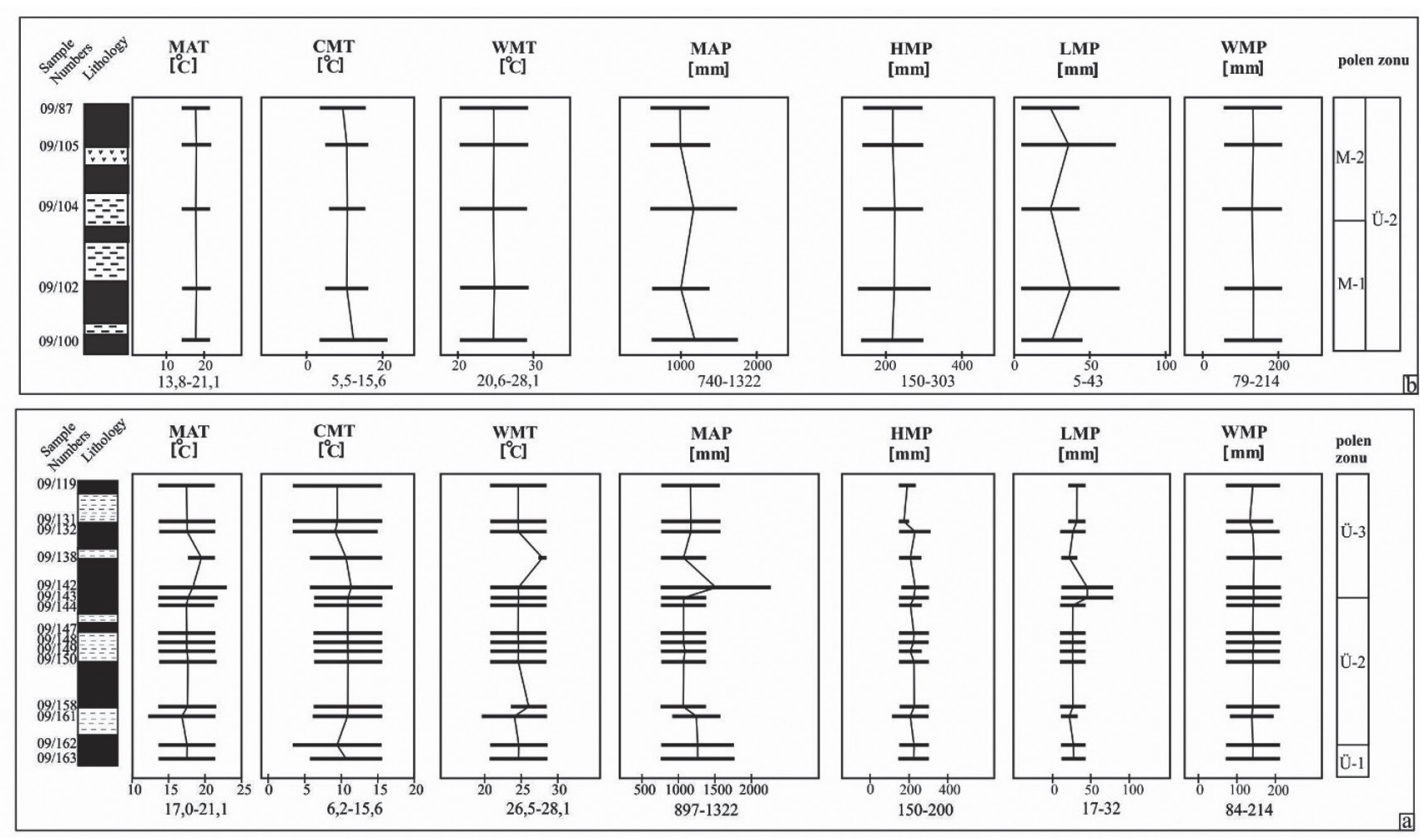

Şekil 7. (a) Ünsa karotundan elde edilen sayısal iklim sonuçları; (b) Metehan kesitinden elde edilen sayısal iklim sonuçları.

Figure 7. (a) Quantitative palaeoclimate data from the Ünsa well; (b) Quantitative palaeoclimate data from the Metehan section (b).
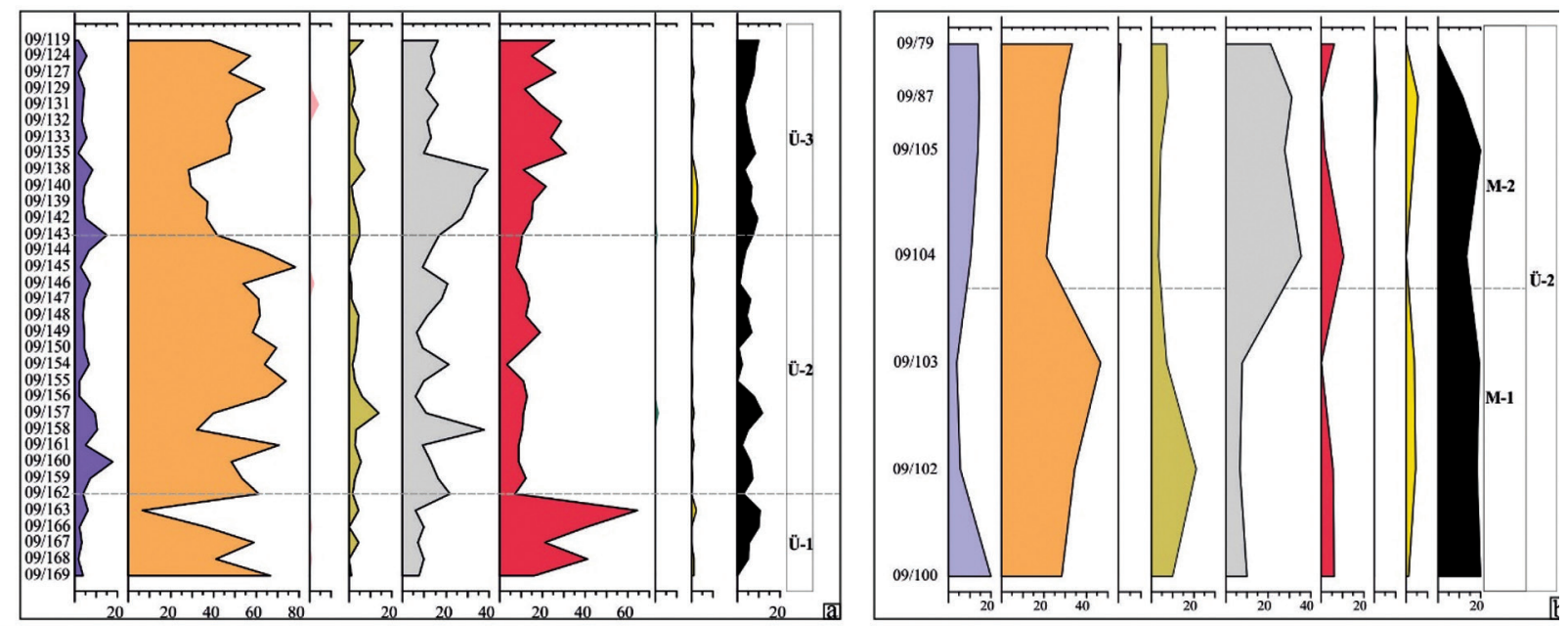

Mega-mesotermik elemantar $\square$ Vesotermik elemanlar $\square$ Mikrotermik

Şekil 8. Ünsa (a) ve Metehan (b) alanlarındaki polenlerden elde edilen paleoekolojik diyagramları. Polen taksaları Suc, 1984, Jiménez-Moreno vd. 2005 'nin ekolojik kriterlerine göre gruplandırılmıştır.

- Mega-mezotermik elemanlar (subtropik): Taxodiaceae, Engelhardia, Myrica, Sapotaceae, CastaneaCastanopsis, Cyrillaceae-Clethraceae

- Cathaya

- Mezotermik elemanlar (1l1k sicak): yaprak döken Quercus, Carya, Pterocarya, Oleaceae, Carpinus, Ostrya, Zelkova, Ulmus, Acer, Liquidambar, Alnus, Palatanu/Salix, Nyssa, Ilex, Betula ve Sequoia 
- Pinus ve ayrılmamış Pinaceae

- Mezo-mikrotermik elemanlar (serin sicak): Cedrus

- Mikrotermik element (serin): Picea

- Akdeniz kurakçılları: Rhus

- Her dem yeşil Quercus

- Cupressaceae

- Otsullar: Poaceae, Chenopodiaceae, Asteraceae, Ephedra ve Brassicaceae.

Figure 8. Synthetic pollen diagrams of Ünsa (a) and Metehan (b) areas. Pollen taxa have been grouped on the basis of ecological criteria (acc. Suc, 1984, Jiménez-Moreno et al. 2005).

- Mega-mesothermic elements (subtropical): Taxodiaceae, Engelhardia, Myrica, Sapotaceae, CastaneaCastanopsis, Cyrillaceae-Clethraceae

- Cathaya

- Mesothermic elements (warm temperate): deciduous Quercus, Carya, Pterocarya, Oleaceae, Carpinus, Ostrya, Zelkova, Ulmus, Acer, Liquidambar, Alnus, Palatanu/Salix, Nyssa, Ilex, Betula and Sequoia

- Pinus and indetermined Pinaceae;

- Meso-microthermic element (cool temperate): Cedrus

- Microthermic element (cool): Picea

- Mediterranean xerophytes: Rhus

- Evergreen Quercus

- Cupressaceae

- Herbs and shrubs: Poaceae, Chenopodiaceae, Asteraceae, Ephedra and Brassicaceae.

\section{SONUÇLAR}

$\mathrm{Bu}$ çalışma ile aşağıda belirtilen sonuçlar elde edilmiştir.

1) Kalkım-Gönen Havzasında palinolojik verileri yeni örneklerle artırmak amacıyla, Ünsa ve Metehan istifleri incelenmiştir. Her iki kesitin litolojileri benzer özelliklere sahip olup, volkanik katkı1ı ince kırıntılı tortullar ve linyitli çökellerden oluşmaktadır.

2) Ünsa sondaj örneklerinin sporomorf içerikleri zengin olup, genellikle ayrılmamış Pinaceae, Cupressaceae gibi konifer ormanı bitkileri ile Alnus gibi 1rmak kenarı bitkilerinin çok yoğun olduğu gözlenmektedir. Karışık orman topluluğunun temel bitkileri Engelhardia, her dem yeşil Quercus ve Quercus spp., dir. Ancak daha düşük oranda bulunmaktadır. Polen yüzdelerindeki değişim üç farklı yersel polen zonunu göstermektedir (Ü-1/3).

3) Metehan sporomorf toplulukları da tıpkı Ünsa sporomorf topluluklarında olduğu gibi konifer ormanı, karışık orman topluluğu bitkileri ve ırmak kenarı bitkilerince zengindir. Topluluklarda bol miktarda ayrılmamış Pinaceae, Quercus spp. ve Alnus bitkileri bulunmaktadır. Polen yüzdeleri iki farklı yersel alt zonun varlığını belirtir. Bu alt zonlar, Ünsa topluluklarında ayırt edilen Ü-2 zonuna karşıllk gelmektedir. $\mathrm{Bu}$ sonuç, Ü-2 zonunda, M-1 ve M-2 alt zonlarında Cupressaceae bitkisinin düşük yüzdeli oluşu ile açıklanabilir. Ayrıca Metehan sporomorf topluluklarında tanımlanan her dem yeşil Quercus ve Quercus spp bitkilerinin bazı örneklerde yüksek yüzdeli oluşu ve aynı formların Ü-2 zonundaki bazı örneklerde benzer şekilde bol miktarda bulunmasıyla paralellik göstermektedir.

4) Sayısal paleoiklim sonuçları ve bitki toplulukları, linyit içerikli tortulların çökelimi süresince nemli, yağışlı ve sıcak bir iklimin varlığını göstermektedir. 


\section{KATKI BELIRTME}

$\mathrm{Bu}$ çalışma Dokuz Eylül Üniversitesi BAP 2009.KB. FEN.021 numaralı bilimsel araştırma projesi tarafından desteklenmiştir. Yazarlar, arazi çalışmalarında yardımcı olan Erhan Akman'a ve sporomorfların tanımlanmasında yardımlarını esirgemeyen Prof. Dr. Funda Akgün'e teşekkürü borç bilirler. Araştırıcılar, yapıcı eleştirileriyle katkı sağlayan hakem Doç Dr. Nazan Yalçın Erik'e teşekkür eder.

\section{EXTENDED ABSTRACT}

There are many Cenozoic coal basins in western Anatolia (e.g., Soma, Çan, Şahinali basins). The vast majority of these basins formed during the Miocene in the lacustrine environments. Oligocene lignites are also available in the northwest Anatolia (Thrace Basin). Recent studies indicate that these lignite-bearing sediments in paralic and limnic characters were accumulated during the late Rupelian-Chattian ("middle"-Late Oligocene) (İslamoğlu et al., 2010; Akgün et al., 2013). In addition, these coaly deposits were thought to be only in the region of Thrace. However the situation is the case and it has been stated that these Oligocene lignites reached to the Biga Peninsula, south of Thrace Basin (Akgün et al., 2013). Economic coal formations in the Biga Peninsula are located in the Çan Basin dated as 15-20 ma (Early-Middle Miocene) by Ediger (1990) who correlated the palynological assemblage defined in the Çan Basin with the "Eskihisar sporomorph association” of Benda (1971). The Kalkım-Gönen Basin is located about $50 \mathrm{~km}$ southeast of the Çan Basin. In the area there are private coal companies producing the lignites. The name of the Soma Formation was suggested by Nebert (1968) who described the lignite-bearing fine grained clastics with volcanics in the Soma Basin around $130 \mathrm{~km}$ southeast of the Kalkım-Gönen
Basin. This name was also used for the present study. In the area, lignite-bearing deposits expose well in the open pit mines. The sediments mainly consist of fine grained deposits with volcanic intercalations. The Late Oligocene-Early Miocene has been suggested by Üçbaş Durak and Akkiraz (in press) for these coaly sequences according to ${ }^{40} \mathrm{Ar}{ }^{{ }^{9} \mathrm{Ar}}$ analysis proofed from the Danişment, Linfa and Bengiler localities of the basin. This study explains the palaeoecological aspects of the other locaties, Ünsa and Metehan. Ünsa open pit mine is located at the mid-point between Kalkım and Gönen. The sequence is made up of coaly finegrained deposits with volcanics. Sediments expose as a vertical position in some places. Private company, Ünsa mining, drilled a borehole to discover economical lignite formations about 187 $m$ total thickness. The sediments in the core consist of lignites with various thickness, sandstones and volcano-clastic deposits. Metehan open pit mine is located about $12 \mathrm{~km}$ northeast of the Ünsa area. The sequence is made up of mudstone, claystone, thin to thick bedded lignite levels, volcano-clastic intercalations. The sediments undertook a dense deformation leading to folds and fractures. Orientation of the fold axis is northeast-southwest direction. In this study, a partial section about $30 \mathrm{~m}$ total thickness was measured and palynologically sampled.

Ünsa palynological assemblages are characterized by high quantities of conifers such as undifferentiated Pinaceae and Cupressaceae, mixed mesophytic forest such as Quercus spp., and riparian plants such as Alnus. Spores, herbaceous and swamp plants are in negligible quantities. According to changes in pollen concentrations three local pollen zone may be distinguished along the sequence. $\ddot{U}-1$ zone is represented by high amounts of Alnus, Cupressaceae and undifferentiated Pinaceae. The percentages of the Castanea-Castanopsis, Engelhardia and Quercus spp., are lesser. $\ddot{U}-2$ zone is characterized by 
common occurrence of Alnus and undifferentiated Pinaceae. In this zone, the pollen Cathaya, Cedrus, Picea, Pinus haploxylon tip, Pinus diploxylon, Cyillaceae-Clethraceae, deciduous Quercus, Fagus, Carpinus, Oleaceae, Betula, Acer, Pterocarya, Myrica and Ephedra appear. The percentages of the Cupressaceae decrease here. $\ddot{U}$-3 zone is distinguished by high quantities of Pinaceae, Cupressaceae and Alnus.

Metehan sporomorphassemblages include low diversification compared to Ünsa associations and are mainly represented by the elements of coniferous forest, mixed mesophytic forest and riparian forest. Pollen counts indicate two different sub zones (M-1 and M-2) corresponding to $\ddot{U}-2$ zone of the Ünsa assemblages. Sub zone M-1 is distinguished by high quantities of evergreen Quercus, Quercus spp., and Alnus. Pollen of Engelhardia, Cupressaceae and Carpinus occur constantly, but in minor amounts. The samples of this sub zone may be correlated with samples located lower side of the $\ddot{U}-2$ zone. $M-2$ sub zone corresponds to the upper part of the $\ddot{U}-2$ zone, and includes high quantities of undifferentiated Pinaceae and Quercus. Palynological data from the Ünsa and Linfa areas indicate a dense forest cover including conifers, mixed mesophytic forest and riparian forest. Mixed mesophytic forest consists mainly of Quercus, Castanea-Castanopsis and Engelhardia. Alnus is the main component of the riparian vegetation together with Ulmus, Zelkova, Pterocarya, Carya and Liquidambar. Herbaceous and swamp plants and spores are in low quantities. Quantitative palaeoclimate data and palaeoecological groups of palynomorphs indicate that warm and humid conditions existed during the deposition of Kalkım-Gönen Basin. The presence of mega-mesothermic plants such as Engelhardia, Castanea-Castanopsis, CyrillaceaeClethraceae and Myrica confirms this result.

\section{DEĞINILEN BELGELER}

Akçay, E., Dönmez, M., Ilgar, A., Duru, M. ve Pehlivan, Ş., 2008. 1:100.000 ölçekli Türkiye jeoloji haritaları-Bandırma-H19 paftası, MTA yayın no: 103, 26.

Akgün, F., Alişan, C. ve Akyol, E., 1986. Soma Neojen stratigrafisine palinolojik bir yaklaşım, Bulletin of the Geological Society of Turkey, V. 29, 13-25.

Akgün, F., Kayseri, M.S. and Akkiraz, M.S., 2007. Paleoclimatic evolution and vegetational changes from the Oligocene to Miocene in Turkey, NECLIME Annual Meeting, Palaeogeography, Palaeogeography, Palaeoclimatology, Palaeoecology, 253, 56-90.

Akgün, F., Akkiraz, M. S., Üçbaş., S. D., Bozcu, M., Kapan-Yeşilyurt, S. and Bozcu, A., 2013. Oligocene Vegetation and Climate Characteristics in North-west Turkey: data from the Southwestern part of the Thrace basin, Turkish Journal of Earth Sciences, 22, 277-303.

Bat1, Z., 1996. Palynostratigraphy and coal petrography of the Upper Oligocene lignites of the Northern Thrace Basin, NW Turkey. PhD Thesis, Middle East Technical University, Ankara, Turkey [unpublished].

Benda, L., 1971. Grundzuge einer pollenanalytischen Gliederung des Turkischen Jungtertiars (Kanozoikum und Braunkohle der Turkei) 4. Beihhefte zum Geologischen Jahrbuch 113, 1-46.

Bozcu, M., Akgün, F., Gürdal, G., Bozcu, A., Kapan Yeşilyurt, S., Karaca, Ö. and Akkiraz, M.S., 2015. Evolution of Çan-Etili (Çanakkale-NW Turkey) Lignite Basin: Sedimantology, Petrology, Palynology and Lignite Characterization. International Journal of Sediment Research, 30, 3, 197-203.

Demirtaş, F., Bozcu, M., Koşun, E. and Akkiraz, M. S., 2015. Petrography and palynology of Late Oligocene and Middle Miocene coals in the Gelibolu peninsula, NW Turkey. Turkish Journal of Earth Sciences, 24, 383-397.

Duru, M., Pehlivan, Ş., Ilgar, A., Dönmez, M. ve Akçay, A. E., 2007. 1:100.000 ölçekli Türkiye jeoloji haritaları-Ayvalık-İ17 paftası. Maden Tetkik ve Arama Enstitüsü Dergisi, 98, 1-36.

Ediger, V. S., 1990. Paleopalynology of coal bearing Miocene sedimantry rocks associate with volcanics 
of the Biga Peninsula (NW Turkey) and the effect of volcanism on vegetation. Neues Jahrbuch für Geologie und Paläontologie, Abhand, 180, 259277.

Ercan, T., Ergül, E., Akçören, F., Çetin, A., Granit, S. ve Asutay, J., 1990. Balıkesir-Bandırma jeolojisi, Tersiyer volkanizmasının petrolojisi ve bölgesel yayılımı. Maden Tetkik ve Arama Enstitüsü Dergisi, 110, 113-130.

Ersoy, E.Y., Çemen, İ., Helvacı, C. and Billor, Z., 2014. Tectono-stratigraphy of the Neogene basins in Western Turkey: Implications for tectonic evolution of the Aegean Extended Region. Tectonophysics, 635, 33-58.

Gemici, Y., Akyol, E., Akgün, F. ve Seçmen, Ö., 1991. Soma kömür havzası fosil makro ve mikroflorası. Maden Tetkik Arama Dergisi, 112, 161-178.

Genç, Y., 1998. Başçatak-Akdağmadeni(Yozgat)Zn-Pb$\mathrm{Cu}$ sulfide deposit: an example of metamorphosed sulfide deposit in the Akdağmadeni massif. Third International Turkish Geology Symposioum Abstracts book. 69, Ankara.

Grimm, E., 1994. Tilia and Tiliagraph Pollen Diagramming Program. Illinois State Museum, Springfield, IL.

İnci, U., 1984. Demirci ve Burhaniye bitümlü şeyllerinin stratigrafisi ve organik özellikleri: Türkiye Jeoloji Kurumu Bülteni, 5, 27-40.

İnci, U., 1998. Miocene synvolcanic alluvial sedimentation in lignite-bearing Soma Basin,Western Turkey. Turkish Journal of Earth Sciences, 7(2), 63-78.

İnci, U., 2002. Depositional evolution of Miocene coal successions in the Soma coalfield, western Turkey International Journal of Coal Geology 51, 1-29.

İslamoğlu, Y., Harzhauser, M., Gross, M., JiménozMoreno, G., Coric, S., Kroh, A., Rögl, F. and Made, J.V.D., 2010. From Tethys to Eastern Paratethys: Oligocene depositional environments, paleoecology and paleobiogeography of the Thrace Basin (NW Turkey). International Journal of Earth Sciences (IJES), 99(1), 183-200.

Jiménez-Moreno, G., Rodriguez-Tovar, F.J., PardoIguzquiza, E., Fauquette, S., Suc, J.-P. \& Müller, P. (2005). High-resolution palynological analysis in late early-middle Miocene core from the Pannonian Basin, Hungary: climatic changes, astronomical forcing and eustatic fluctuations in the Central Paratethys. Palaeogeography, Palaeoclimatology, Palaeoecology, 216(1), 73-97.

Kaya, O., Ünay, E., Göktaş, F. and Saraç, G. 2007. Early Miocene stratigraphy of central west Anatolia, Turkey: implications for the tectonic evolution of the eastern Aegean area. Geological Journal, 42(1), 85-109.

Mosbrugger, V. and Utescher, T., 1997. The Coexistence Approach-a method for quantitative reconstructions of Tertiary terrestrial paleoclimate data using the plant fossils. Palaeogeography, Palaeoclimatology, Palaeoecology, 134, 61-86.

Nebert, K., 1978. Linyit içeren Soma Neojen Bölgesi, Batı Anadolu. Maden Tetkik ve Arama Enstitüsü Dergisi, 90, 20-69.

Okay, A. I., Siyako, M., \& Bürkan, K. A. (1990). Biga Yarımadası'nın jeolojisi ve tektonik evrimi. Türkiye Petrol Jeologları Derneği Bülteni, 2(1), 83-121.

Pehlivan, Ş., Duru, M., Dönmez, M., Ilgar, A., Akçay, E., Erdoğan, K. ve Özer, D., 2007. 1:100.000 ölçekli Türkiye jeoloji haritaları-Bandırma-H19 paftası. Maden Tetkik ve Arama Enstitüsü Dergisi, 96,1-40.

Selim, H. H., Tüysüz, O. ve Barka A. A., 2006. Güney Marmara Bölümünün Neotektoniği. İstanbul Teknik Üniversitesi Dergisi, 5, (1) 151-160.

Siyako, M., Bürkan, K. A. ve Okay, A., 1989. Biga ve Gelibolu Yarımadaları'nın Tersiyer jeolojisi ve hidrokarbon olanakları. Türkiye Petrol Jeologları Derneği Bülteni, 1/3, 183-200.

Suc, J.P. (1984). Origin and Evolution of the Mediterranean vegetation and climate in Europe. Nature, 307, 429-432.

Üçbaş Durak, S. D. ve Akkiraz, M. S., (2016). Late Oligocene- Early Miocene palaeoecology based on pollen data from the Kalkım-Gönen Basin (Northwest Turkey). Geodinamica Acta.

$\begin{array}{ll}\text { Makale Geliş Tarihi } & : \text { 4 Nisan } 2016 \\ \text { Kabul Tarihi } & : \text { 31 Mayis } 2016 \\ & : \text { A April 2016 } \\ \text { Received } & : \text { 31 May 2016 }\end{array}$




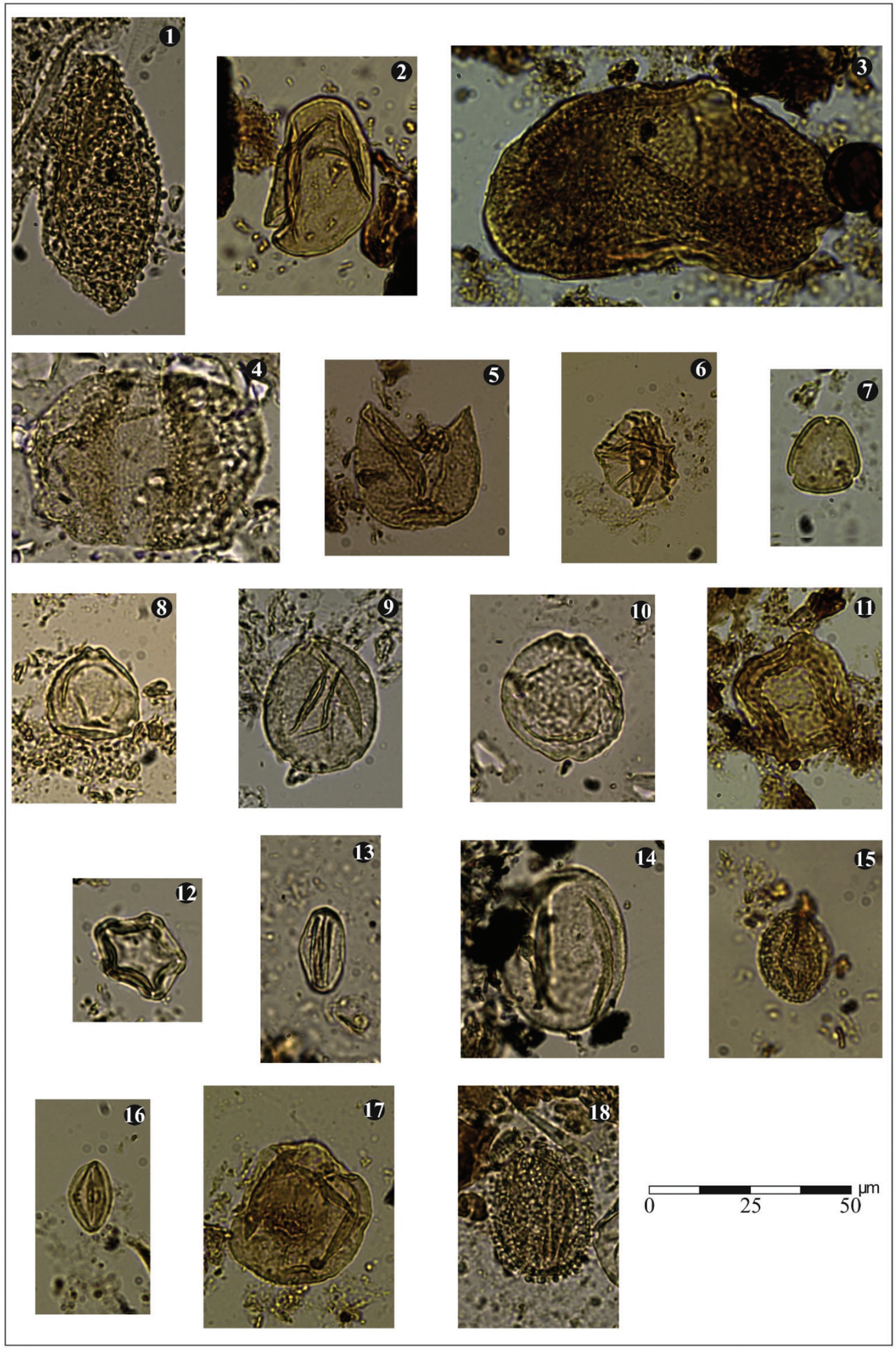




\section{LEVHA I}

Kesitlerden seçilen sporomorf fotoğrafları. Her bir formun örnek numaraları ve bulunduğu zonlar belirtilmiştir. Şekiller için ölçek $25 \mu \mathrm{m}$.

1 Osmunda, örnek 09/135; Ünsa topluluklar1; Ü-3 zonu

2 Polypodiaceae/Thelypteridaceae, örnek 09/79; Metehan topluluklar1; M-2 alt zonu

3 Cedrus, örnek 09/132; Ünsa toplulukları; Ü-3 zonu

4 Pinus haploxylon tip, örnek 09/146; Ünsa toplulukları; Ü-2 zonu

5 Cupressaceae, örnek 09/163; Ünsa toplulukları; Ü-1 zonu

6 Poaceae, örnek 09/103; Metehan topluluklar1; M-1 alt zonu

7 Engelhardia, örnek 09/87; Metehan toplulukları; M-2 alt zonu

8 Betula, örnek 09/87; Metehan toplulukları; $\mathrm{M}-2$ alt zonu

9 Celtis, örnek 09/155; Ünsa toplulukları; Ü-2 zonu

10 Ulmus, örnek 09/140; Ünsa toplulukları; Ü-3 zonu

11 Zelkova, örnek 09/143; Ünsa topluluklar1; Ü-3 zonu

12 Alnus, örnek 09/145; Ünsa toplulukları; Ü-2 zonu

13 Fagaceae, örnek 09/100; Metehan topluluklar1; M-1 alt zonu

14 yaprak döken Quercus, örnek 09/100; Metehan topluluklar1; M-1 alt zonu

15 Platanus/Salix, örnek 09/87; Metehan topluluklar1; M-2 alt zonu

16 Castanea-Castanopsis örnek 09/158; Ünsa topluluklar1; Ü-2 zonu

17 Fagus, örnek 09/162; Ünsa toplulukları; Ü-2 zonu

18 Ilex, örnek 09/133; Ünsa topluluklar1; Ü-3 zonu

\section{PLATE I}

Sporomorph photos from all sections indicating sample numbers and local pollen zones. Scale is $25 \mu \mathrm{m}$ for the figures.

1 Osmunda, sample 09/135; Ünsa assemblages; Ü-3 zone

2 Polypodiaceae/Thelypteridaceae, sample 09/79; Metehan assemblages; M-2 sub zone

3 Cedrus, sample 09/132; Ünsa assemblages; Ü-3 zone

4 Pinus haploxylon tip, sample 09/146; Ünsa assemblages; Ü-2 zone

5 Cupressaceae, sample 09/163; Ünsa assemblages; Ü-1 zone

6 Poaceae, sample 09/103; Metehan assemblages; M-1 sub zone

7 Engelhardia, sample 09/87; Metehan assemblages; M-2 sub zone

8 Betula, sample 09/87; Metehan assemblages; M-2 sub zone

9 Celtis, sample 09/155; Ünsa assemblages; Ü-2 zone

10 Ulmus, sample 09/140; Ünsa assemblages; Ü-3 zone

11 Zelkova, sample 09/143; Ünsa assemblages; Ü-3 zone

12 Alnus, sample 09/145; Ünsa assemblages; Ü-2 zone

13 Fagaceae, sample 09/100; Metehan assemblages; M-1 sub zone

14 yaprak döken Quercus, sample 09/100; Metehan assemblages; M-1 sub zone

15 Platanus/Salix, sample 09/87; Metehan assemblages; M-2 sub zone

16 Castanea-Castanopsis sample 09/158; Ünsa assemblages; Ü-2 zone

17 Fagus, sample 09/162; Ünsa assemblages; Ü-2 zone

18 Ilex, sample 09/133; Ünsa assemblages; Ü-3 zone 